\title{
Ethnic identity and scholastic effort: a multifaceted approach
}

\author{
Giuseppina Autiero
}

Correspondence: pinaut@unisa.it Department of Economics and Statistics and CELPE, University of Salerno, Via Giovanni Paolo II, 132 84084 Fisciano, SA, Italy

\begin{abstract}
When one analyses the influence of social identity on scholastic effort, ethnic identity largely contributes to determine it. In this paper, ethnic identity is meant as the attachment to one's cultural heritage and the adaptation to host societies; this allows considering how conflicting demands and social pressure from parents, peers, ethnic community and host societies influence children's effort. Attention is also paid to the locus of control; thereby, the effects of the interaction between the social context—ethnic identity — and personal traits such as the locus of control are considered. The analysis is developed through a theoretical model whose results partly show that children's effort may be influenced positively by parents with strong attitudes towards adaptation and negatively by their peers in school who belong to marginalized groups vulnerable to discrimination and convinced that school does not improve one's socio-economic status. Nevertheless, the drawbacks of the social context can be counterbalanced by a strong locus of control.
\end{abstract}

JEL Classification: 120, 129, Z10

Keywords: Scholastic effort, Ethnic identity, Personal identity

\section{Introduction}

Great attention has been recently paid to the determinants of immigrants' attachment to their cultural background and of their identification with host countries (Zimmermann et al. 2006). Scholarly analysis has also focussed on the transmission and persistence of ethnic identity through parents' cultural influences and socialization within family and wider social contexts including neighbourhoods and peer groups (Bisin et al. 2006; Chiswick 2009). The emphasis on identity formation and transmission is justified by the role that ethnic identity plays in individual economic performances. In this respect, some economic studies have investigated on how the identification with the culture of home and host countries influences immigrants' and their children's labour market outcomes. There is evidence that a strong ethnic identity lowers the probability of being employed for immigrants (Constant et al. 2006; Bisin et al. 2011) and that at the time of arrival, immigrants earn a lower wage as compared to native born (Adsera and Chiswick 2007). Interestingly, ethnic minority identity may work in opposite directions as, on the one hand, it facilitates the access to labour market opportunities for young individuals who participate in ethnic networks (Casey and Dustmann 2010) and, on the other, it often means participation in

(c) The Author(s). 2017 Open Access This article is distributed under the terms of the Creative Commons Attribution 4.0 International License (http://creativecommons.org/licenses/by/4.0/), which permits unrestricted use, distribution, and reproduction in any medium, provided you give appropriate credit to the original author(s) and the source, provide a link to the Creative Commons license, and indicate if changes were made. 
poor social networks with scarce information on job opportunities (Battu et al. 2007). Yet labour market performance is largely affected by individuals' schooling, which in turn depends on ethnic identity as well (Akerlof and Kranton 2002). In this respect, a strand of literature has taken into consideration how parents' ethnic identity influences the scholastic performance of their children. For instance, in Germany, mothers' identification with the host country and fathers' identification with the home country positively affects school achievements of second-generation children (Schüller 2015). Strong ethnic identity may lead black adolescents to choose mostly same-race friends rather than also white friends, which undermines their performance in school, though a high level of education of their parents reduces this negative influence (Patacchini and Zenou 2006). Ethnic identity directly determines individual scholastic performance; in this respect, Nekby et al. (2009) demonstrate that men with an integrated identity who are attached both to their home background and to the majority culture have a higher probability of completing tertiary education.

Drawing on the literature that considers the influence of ethnic identity on schooling, the contribution of this paper is characterized by three main aspects. First, though the starting point is Akerlof and Kranton's (2002) model of educational choice, in the theoretical model presented here which follows Autiero (2015), ethnic identity directly determines achievement motivations, which is in line with part of the psychology literature. Second, it is analysed how the interplay between the adaptation to host societies and the influence of home country cultures determines children's scholastic effort. Finally, attention is given to the locus of control; thereby, it is possible to examine how the external context through ethnic identity and a specific aspect of individual personal traits captured by the locus of control affect effort in school. Perceived discrimination also plays a significant role by influencing both the adjustment to host societies and the locus of control. Therefore, in the following section, we survey the approaches to ethnic identity in line with the cross-cultural psychology literature in order to understand how ethnic identity may shape children's approach to schooling in the host country. In Section 3, the analysis goes on by considering how ethnic identity and the locus of control may affect children's motivation to exert effort in school in more detail. Subsequently, in Section 4, it is proposed a simple theoretical model where it is introduced the interaction among the components of ethnic identity and the locus of control embodying also perceived discrimination. How such interaction may lead to different levels of scholastic effort emerges from the results in Section 5. Finally, conclusions from this analysis are drawn.

\section{Ethnic identity from a psychological perspective}

Some of the empirical contributions previously mentioned point to the fact that ethnic identity partly determines children's scholastic performance; such influence may occur in several ways, which is possible to understand by firstly clarifying what is generally meant by ethnic identity. From the perspective of cross-cultural psychology, there are three broad theoretical approaches to ethnic identity emphasizing different aspects of the relationship of individuals with the minority group to which they belong (Frable 1997). A strand of literature considers the phases of ethnic identity development ranging from exploring the culture specific to one's ethnic group to the commitment to its values and goals (Phinney 1989). Social identity theory instead considers the dynamics 
of intergroup relations through ingroup/outgroup comparisons, where the degree of ethnocentrism of the minority group is associated with discriminatory intergroup behaviour triggered either by conflicting interests or by the need of the dominant group to preserve its positively valued distinctiveness from the low-status group (Tajfel and Turner 1979). Finally, the acculturation approach takes into account how the minority group reacts to the culture of the mainstream society (Phinney 1990); it suggests two types of theoretical lines both taking ethnic identity as 'embracing various aspects, including self-identification, feelings of belongingness and commitment to a group, a sense of shared values, and attitudes toward one's own ethnic group' (Phinney et al. 2001). According to the former, the process of acculturation leads to the weakening of individuals' ethnic culture as they strengthen the identification with the culture of the host country. The latter alternatively maintains that individuals preserve their own cultural heritage and at the same time adapt to the host society; it is based on two-dimensional models where maintaining one's own ethnic identity is independent from the assimilation of the new culture. In this respect, acculturation orientations can be characterized by integration, assimilation, separation and marginalization; integration implies that individuals value maintaining both the culture of origin and the adaptation to the host society, whereas with assimilation, they do not consider the preservation of their ethnic culture of value and only seek integration into the mainstream society. Finally, marginalized individuals show little interest in preserving both their own culture and adaptation while separated individuals consider only the preservation of their culture as valuable (Bourhis et al. 1997; Phinney et al. 2001). In this two-dimensional analysis, attachment to ethnic culture and adaptation to host societies depend also on the features of the local context to which people belong like the concentration of a specific ethnic group, the influence of family background, neighbourhood and peer effects (Phinney et al. 2001).

\section{Ethnic identity, locus of control and scholastic performance}

As to the meaning of ethnic identity, we decided to follow the strand of acculturation that embraces both the attachment to one's own cultural heritage and the adaptation to the host society since this allows considering the multiple facets of how ethnic identity may shape youth behaviour in school. This approach suggests that children living in an immigrant family are often faced with conflicting demands and social pressures from their parents, peers, ethnic communities and host societies and that they mediate among them by developing different attitudes towards adaptation to school. In particular, ethnic socialization practices of parents and ethnic communities influence the meaning and the negative or positive value children attach to their ethnicity and their adjustment to the dominant culture. The process of children's adaptation is mediated by parent-child relationship as ethnic minority parents transmit their own cultural beliefs, attitudes, values and expectations related to child rearing to the family. Childrearing practices also concern school adjustment, as parents may be concerned about their children's socio-economic upward mobility and choose an integration path for them. Therefore, they support their progression in school by transmitting values and expectations that emphasize the importance of adjusting to the mainstream culture through schooling. This shapes children's achievement motivations and attitudes towards school (Yasui and Dishion 2007). Nevertheless, values on the importance of 
schooling may differ across ethnic groups, for instance, Southeast Asians value selfreliance and achievement and, generally, Asian youth give priority to good scholastic performance as they feel very responsible to their immigrant parents. Moreover, Asian Americans have optimistic cultural expectations about schooling benefits in terms of social mobility (Hirschman and Lee 2005; Kao and Thompson 2003), and youths react to discrimination by overperforming in school (Kao and Thompson 2003). Interestingly, Punjabi parents, on the one hand, keep their children away from their white peers fearing they will become too Americanized and, on the other, pressure them to conform to school rules and to ignore racism and prejudices (Hirschman and Lee 2005; Portes and Zhou 1993), whereas African Americans often tend to develop their ethnic identity in opposition to the dominant group and to preserve it from integration into the mainstream culture as their identity is rooted in the experience of discrimination. In this case, parents do not transmit values strengthening their children's achievement motivations, as they do not expect that in the dominant society, education will lead to socio-economic upward mobility (Fordham and Ogbu 1986).

Notably, ethnic differences in the importance of schooling may depend on the fact that parents' child-rearing and practices are influenced not only by their attitudes towards adaptation but also by the cultural values specific to their ethnic background. The latter conditions the extent of parents' attention and responsiveness to children's needs and their expectations for and control of children's behaviour, all factors that contribute to shape scholastic performance (Yasui and Dishion 2007). For instance, East Asian culture mainly based on Confucian ethics values hierarchical relationships within families where parents discipline and control their sons, who in turn have to respect and obey their parents, fulfil their expectations and honour the family name; in particular, the involvement of parents in following children's progress in school is very high and academic success is a way to meet their expectations. Latin American culture for child-rearing gives importance to the ties with nuclear family members and extended family networks, which take care of and control children. Familial support is crucial for successful performance in school as it encourages youth to pursue educational goals (Yasui and Dishion 2007). Thus, parents who are more integrated and also attached to their ethnic culture that positively shapes child-rearing and especially scholastic performance may significantly stimulate children to achieve. While parents who show a separated acculturation style with attachment only to their ethnic background, which in addition shows strong incongruities with mainstream school culture, may negatively affect children's adaptation to school and weaken their motivation.

Aside from parental influence, ethnic community plays a key role as the assimilation into the values and norms of the community also determines the form of youths' adjustment to the host society and the part of society they assimilate (Portes and Zhou 1993). Adjustment may encompass, for instance, integration and therefore both maintaining the culture of origin and adaptation to the mainstream culture while separation often means assimilation into the adversarial culture of marginalized social groups. Importantly, a vital ethnic community acting as a distinctive and collective entity may make children develop a positive attitude towards their group and less vulnerable to the orientations of the host society like segregation (Bourhis et al. 1997; Phinney et al. 2001). In this respect, some Mexican students belonging to a community with strong cultural ties with both their home country and the USA were able to overcome 
discrimination and to perform well in school (Portes and Zhou 1993). It may also happen that newly arrived youths may become part of earlier generations' marginalized groups in their co-ethnic community and assimilate their culture. This is the case of the integration of some Mexican students in the group of Chicanos, native-born Mexican Americans, and of some Haitian adolescents in the minority youths in American inner-city schools (Portes and Zhou 1993). Identifying with these groups has led to the assimilation of their values, which usually disregard education as a means to advance one's socio-economic status due to the prejudices and discrimination of the host society (Hirschman and Lee 2005). The fact that immigrant students, despite parental influence, may end up integrating into marginalized groups of their co-ethnic community may also depend on the school socio-economic status (SES). Low SES schools often are segregated and characterized not only by lower quality courses but also by very low expectations of significant others like peers and teachers on students' attainment (Hirschman and Lee 2005). There may be a negative influence of school peers and teachers on immigrants' integration and social expectations as children end up believing they will not succeed in school and integrate in the host society.

In this context of analysis, it is important to stress that the exclusion of a minority group by a dominant group may cause psychological costs in the process of identification with the mainstream culture (Brown and Capozza 2006). In school, this may imply that pupils belonging to a minority group bear a psychological cost in presence of discrimination, which impinges on their scholastic performance.

Children scholastic performance is also determined by personal traits shaping personal identity generally less permeable to social influences differently from ethnic identity. The locus of control is a component of personal identity particularly relevant to our analysis as it affects individual motivations in that it concerns the extent to which an individual believes that her own actions or characteristics influence outcomes (Rotter 1966; Haußer 1995). In the case of education, effort and hard work are not believed to improve academic achievements, which are rather ascribed to luck. Yet the locus of control is not completely independent from being part of a minority group as, for instance, external attitudes may be influenced by children's consideration that scholastic achievement is strongly dependent on perceived discrimination. This occurred to some African American students coming from low-quality schools when they reached the college level and realized that they were less prepared than the other students who had attended different high schools. In this context, African Americans tended to ascribe their lower performance to external factors they did not control such as discrimination and were convinced that higher effort would not translate in a better performance in school and labour market (van Laar 2000).

In the following part, attention will be focused on a theoretical model where in light of the above considerations, ethnic identity and the locus of control shape youth's motivations to exert effort in school.

\section{The model}

The present model partly draws on the contribution of Akerlof and Kranton (2002) and of Autiero (2015); Autiero and O'Higgins (2016) in analysing the influence of social identity and the locus of control on scholastic effort; nevertheless, we take into consideration ethnic identity with its multidimensionality as a specific aspect of social 
identity. Of relevance to our different approach, in the contribution of Akerlof and Kranton (2002), students decide to identify with a social group in school and the benefits from this choice depend on the self-image characterizing such group. Changes in utility are affected by the distance of individual characteristics and behaviour respectively from the ideal promoted by the social category. Importantly, they choose to follow a specific group and therefore the effort level fitting into it, whereas, in our case in line with Autiero (2015), social identity-precisely ethnic identity—directly affects the utility from scholastic effort $-e_{i}$-by shaping children's motivations to exert effort. This occurs through the internalization of the values transmitted by parents, peers and ethnic community members that determine children's perceived importance given to engaging in academic tasks, which determines the utility from effort. In detail, we characterize a child's ethnic identity in part in terms of adaptation to the mainstream society's school and define it as $I_{O k i}$, which is affected by the acculturation orientations of child $i$ 's parents belonging to the ethnic group $k-I_{k i}$-and of her peers in school belonging to the same ethnic community $-\bar{I}_{k}$; the specification of children's adaptation is $I_{O k i}=I_{k i}^{\beta(D i)} \bar{I}_{k}^{\lambda(D i)}$. Parents giving great importance to integration consider scholastic achievements as a means for their children to integrate into the host country; alternatively, they may think that adaptation to school in the host country will be fruitless in order to achieve socio-economic upward mobility. As already mentioned, parental acculturation orientations shape their offspring's identity through the transmission of the values and cultural expectations either fostering or hampering children's adaptation to school and thus their motivation to achieve. In school, children may frequently be exposed also to the influence of the group of peers sharing a common ethnic socio-economic and cultural background; the acculturation orientations of peers are represented by $\bar{I}_{k}$ and behave similar to the ones of parents. As to parental acculturation orientations $-I_{k i}$-it is important to specify that in a family where parents transmit values strongly oriented towards adaptation through education, their children derive greater utility from scholastic effort; thereby, they meet parental expectations for their behaviour in school. When parents do not give importance to education and achievements in the host society's schools, children are not so driven by the need to comply with the behavioural requirements prescribed by them, which is a source of disutility from effort. This influence on the utility may be either strengthened or weakened by the pressure of their school peers $-\bar{I}_{k}$; for instance, a child identity oriented towards integration due to family influences may be undermined by the interaction with pupils of the same ethnic community who reject the values of the mainstream society. To the contrary, children's positive acculturation orientations are reinforced by similar orientations in their peers. Thus, in the expression defining adaptation, $I_{O k i}=I_{k i}^{\beta\left(D_{i}\right)} \bar{I}_{k}^{\lambda\left(D_{i}\right)}, \beta\left(D_{i}\right)$ and $\lambda\left(D_{i}\right)$ capture the influence of parents and school peers on children's adjustment to schools in mainstream society, respectively; the size of the parameters is affected by children's reactivity and, in particular, by their perceived discrimination $D_{i}>0$ in school in the sense that when they feel more discriminated, this lowers the positive influence of parents on children's adaptation. To the contrary, when parents and/or peers reject adaptation, perceived discrimination strengthens this negative influence.

The other part of ethnic identity $E_{k}$-shortly defined as ethnicity-corresponds to the extent to which the culture of ethnic group $k$ promotes education and academic success; such extent also depends on the consistence of ethnic background with mainstream school culture. Ethnicity embodies the values common to parents and 
community members that they transmit to children through rearing practices. Therefore, the influence of ethnicity on the utility from effort is positive implying that the more favourable to academic progress the culture of origin, the more motivated the children when following the values transmitted by their parents and ethnic community members through rearing practices. The presence of incongruities between home and mainstream school culture weakens the extent to which ethnicity furthers academic progress.

We also consider personal identity; it is individuated by the locus of control, $L_{i}$, which is relevant to scholastic effort in as much as individuals with a sense of competence about their abilities and a stronger feeling of control of success and failure in pursuing their own personal goals are likely to be more motivated in school. Individuals who are more internal locus get greater utility for a given effort level to the extent to which they ascribe academic achievements to their own effort rather than to the external environment.

Importantly, children with some degree of integration bear a psychological cost due to the divergence of individual effort $e_{i}$ from school academic standard $e(S)$, which capture specific knowledge and skills that students must acquire and may also reflect the socio-economic status of schools.

Ethnic identity and the locus of control enter children's utility function as follows:

$$
\begin{aligned}
U_{i}\left(e_{i}, I_{k i}, \bar{I}_{k}, E_{k}, L_{i}, D_{i}\right)= & \alpha\left(e_{i} n_{i}-\frac{1}{2} e_{i}^{2}\right)+(1-\alpha) \\
& \times\left[\begin{array}{c}
\left(I_{k i}^{\beta\left(D_{i}\right)} \bar{I}_{k}^{\lambda\left(D_{i}\right)}+\gamma E_{K}+\phi\left(D_{i}\right) L_{i}\right) e_{i-} \\
-\frac{\vartheta\left(I_{O k i}, E_{k}\right)}{2}\left(e_{i}-e(S)\right)^{2}
\end{array}\right]
\end{aligned}
$$

In (1), $\alpha$ and $(1-\alpha)$-with $\alpha \geq 0$-indicate the relative weights of the standard and identity-driven components of the utility function. When $\alpha=0$, only the identity part counts while if $\alpha=1$, standard cost/benefit considerations prevail; $e_{i} n_{i}$ represents $i$ s marketable skill or human capital with $e_{i}$ corresponding to individual effort and $n_{i}$ to individual ability; ${ }^{1}$ effort cost is $\frac{1}{2} e_{i}^{2}$. The components of identity in brackets before $e_{i}$ show that parents' and peers' acculturation orientations, ethnicity and locus of control affect the utility from a given effort level. As to parents' and peers' acculturation orientations, $I_{k i}$ and $\bar{I}_{k}$ belong to the interval $(1,+\infty)$, respectively. Parameters $\beta\left(D_{i}\right)$ and $\lambda\left(D_{i}\right)$ belong to the interval $(-\infty,+\infty)$ and precisely $\beta\left(D_{i}\right), \lambda\left(D_{i}\right)>0 \quad \forall D_{i}>0$ when parents and peers are in favour of adjustment whereas $\beta\left(D_{i}\right), \lambda\left(D_{i}\right)<0 \forall D_{i}>0$ when they reject adaptation to host countries' schools. In the former case, parents' and peers' influence complement each other in the process of youth's identity adjustment to the dominant culture $\left(\frac{\delta^{2} I_{O K i}}{\delta I_{k i} \delta I_{k}}\right)>0$; in the latter, when either parents or peers reject adjustment as they believe that it will not lead to their socio-economic mobility, the cross derivative is negative. This means that if, for instance, parents are in favour of adaptation and peers reject it, a higher adaptation due to parents' influence raises the utility from effort, which in turn is curbed by the negative impact of rising peers' aversion to adjustment. Importantly, when both parents and peers transmit values in favour of adaptation and perceived discrimination increases, $\beta^{\prime}\left(D_{i}\right)<0$ and $\lambda^{\prime}\left(D_{i}\right)<0$ in the sense that higher perceived 
discrimination weakens children's positive attitude to adjust. While increased perceived discrimination amplifies the impact of the values against adjustment, therefore, $\beta^{\prime}\left(D_{i}\right)<$ $0, \lambda^{\prime}\left(D_{i}\right)<0$ and the negative influence on a child's motivation is stronger than in the previous case.

As to ethnicity, $E_{k}$ is greater than zero and $\gamma \geq 0$. Parameter $\gamma$ may capture the attachment of children to the ethnic culture transmitted by their parents and ethnic community. As to personal traits, it is assumed $L_{i}>0$ and $\phi\left(D_{i}\right)>0$, and when perceived discrimination $-D_{i}$ - becomes stronger, this undermines the influence of internal locus of control on the utility from effort with $\phi^{\prime}\left(D_{i}\right)<0$. The second addend in square brackets corresponds to the psychological cost children bear when their effort diverges from the school standard embodying knowledge and skills that students must acquire in host countries' schools, with $e_{i} \leq e(S)$. The component $\vartheta\left(I_{O k i}, E_{k}\right)$ is the unit cost of a behaviour that does not meet the standard, it is positive and increasing with respect to both children's adaptation and ethnicity with $\vartheta_{I_{O K i}}>0$ and $\vartheta_{E_{k}}>0$ implying that the cost of diverging from the school academic standard $e(S)$ rises when a child becomes more adjusted to the culture of the host country and ethnic culture gives greater importance to education. In the latter case, the presence of incongruities between home and mainstream school culture lowers the extent to which ethnicity promotes education and consequently the cost of diverging from the school standard in the host country. This cost indirectly depends also on the degree of perceived discrimination $D_{i}$, which weakens children's attitudes towards integration or strengthens aversion to adjustment and thereby reduces the psychological cost of diverging from the school's standard $e(S)$.

\subsection{Some results: the influence of ethnic identity, locus of control and perceived discrimination on effort}

Optimal effort is obtained from (1) above and is given by the following expression:

$$
e_{i}^{*}=\frac{1}{\alpha+(1-\alpha) \vartheta\left(I_{o k i}, E_{k}\right)}\left[\alpha n_{i}+(1-\alpha)\left(I_{k i}^{\beta\left(D_{i}\right)} \bar{I}_{k}^{\lambda\left(D_{i}\right)}+\gamma E_{k}+\phi\left(D_{i}\right) L_{i}\right)+(1-\alpha) \vartheta\left(I_{o k i}, E_{k}\right) e(S)\right]
$$

In (2), it is immediately evident that for given $\beta\left(D_{i}\right)$ and $\lambda\left(D_{i}\right)$, peers' opposition to the school culture of the host country- $\lambda\left(D_{i}\right)<0$-compared to an adaptive attitude $-\lambda\left(D_{i}\right)>0$-reduces the influence of a strong propensity of parents to adjust to the mainstream culture determined by $I_{k i}$ with $\beta\left(D_{i}>0\right)$. To the contrary, if the effect of peers on children's identity becomes increasingly oriented towards adaptation, the motivation to exert effort can be weakened by parents' aversion to adjustment with $\beta\left(D_{i}<0\right)$. Therefore, the shortcomings of family background can be overcome by peers' influence in school and vice versa. When both parents and peers tend to discourage adaptation to the host society, this does not facilitate children's adjustment to school and reduces the stimulus for effort.

By considering the two components of identities-adaptation and ethnicity-it is possible to hold that higher values of both adaptation $I_{O k i}$ and ethnicity $E_{k}$ imply that children are strongly integrated as they tend to adjust to mainstream school culture also through their home background, which further strengthens their effort. Moreover, the influence of low children's adaptation $I_{O k i}$ may be counterbalanced by the one of strong 
ethnicity $E_{k}$-and vice versa-as, on the one hand, parental and/or school peers' scarce attitudes towards adaptation undermine children's motivations to achieve in school and, on the other, ethnic culture strongly promoting education offsets this effect. Nevertheless, a low attachment of children to their ethnic culture-lower $\gamma$-may weaken the influence of the cultural values promoted by their parents and ethnic community. Thus, though these values may strongly favour education and academic progress, low attachment to them coupled with an attitude contrary to adjustment to the host country leads to a marginalized ethnic identity and undermines children's motivation. One can obtain lower effort also when youths with a separated identity from the mainstream culture- $I_{O k i}$ close to one-follow only their ethnic culture that gives low value to education, due for instance, to a sharp contrast between home and mainstream school culture. When youths' ethnic identity is characterized by assimilation, they are only interested in adjusting to the host society' school and in integration and are not affected by their home country culture $-\gamma=0$. If this type of disposition becomes stronger, it reinforces the motivation to exert effort though to a lower extent with respect to the case of children's integrated identity.

In relation to the above aspects, as already mentioned, Schüller (2015) underlines that parents' integrated identity based on adjustment to host countries and attachment to ethnic culture plays a relevant role in children's educational attainment. His empirical evidence shows that in Germany, mothers' identification with the host country positively affects children's academic progress as they take care of their scholastic performance, which is made possible by their knowledge of the language and of the German schooling system. Fathers' identification with home culture exerts a similar influence due also to family rules that derive from their background and shape childrearing and practices. Similarly, Nekby et al. (2009) report that in Sweden, men with non-Nordic backgrounds and an integrated identity have a higher probability of completing tertiary education, whereas if they are characterized by either assimilation or separation, the probability is lower. In fact, the families with a bicultural orientation encourage the development of reading and writing abilities both in the host and home country language.

Nevertheless, positive parental influence may be weakened by the negative pressure of peers related to the presence of social networks in schools that are segmented by race. The empirical evidence reported by Mayer and Puller (2008) shows that racial segmentation in school may mainly be driven by preferences for same race friends. The implication is that children may become part of marginalized groups and share their values and expectations concerning the school as a means to move up the social ladder like in the case of the Mexican students who assimilated the culture of Chicanos (Portes and Zhou 1993).

From (2), one can derive the influence of children's ethnic identity, locus of control and perceived discrimination on children's optimal effort respectively (for further details, see the Appendix):

$$
\frac{\partial e_{i}^{*}}{\partial I_{k i}}>0, \frac{\partial e_{i}^{*}}{\partial \bar{I}_{k}}>0, \frac{\partial e_{i}^{*}}{\partial E_{k}}>0, \frac{\partial e_{i}^{*}}{\partial L_{i}}>0, \frac{\partial e_{i}^{*}}{\partial D_{i}}<0, \frac{\partial e_{i}^{*}}{\partial e(S)}>0
$$

From (3), the role of $I_{k i}$ and $\bar{I}_{k}$ is straightforward as children's greater adaptation due to the influence of either parents or school peers, on the one hand, motivates higher 
effort and, on the other, raises the psychological cost of diverging from academic school standard. In the opposite case when the values interiorised by children are against adjustment, they reduce effort as motivations become weaker and psychological costs lower. Ethnicity plays a similar role, for instance, when there are some incongruities between ethnic and mainstream school culture with lower $E_{k}$, motivations may become so frail to induce lower effort; the strength of this effect depends on children's attachment to ethnic culture $\gamma$ (see (6) in the Appendix). In this respect, Hirschman and Lee (2005) through empirical evidence argue that in the Pacific Northwest East Asians (Chinese, Koreans and Japanese), Vietnamese and Cambodians have a strong commitment to education in the host country, though their socio-economic background may be poor. They hold that one of the sources of this behaviour is a higher propensity to adjust rooted in their immigrant optimism relying on the belief that hard work will help their children's socio-economic mobility. Immigrant parents' home background valuing culture may reinforce the positive influence of their attitude to adaptation as Kao and Thompson (2003) emphasize referring to the case of Southeast Asians. As one would expect, perceived discrimination $D_{i}$ lowers effort as it either weakens the adaptation of children's identity to the host country or bolsters their refusal to adjust to mainstream society; it also reduces the influence of the locus of control and thereby the overall motivation to exert effort. Mickelson (1990) documents such influence: she argues that though many American black youths strongly value education, they face the reality that effort will not bring larger opportunities in labour markets, which causes underachievement. This recalls the approach of Fordham and Ogbu (1986), who show that perceived discrimination determines children's development of an oppositional identity and undermines their scholastic effort.

In addition, discrimination lowers the psychological cost of diverging from academic school standard by undermining the adaptation of children's identity to the dominant culture or reinforcing children's opposition to adjustment. As one would expect, lower scholastic standard $e(S)$ often corresponding to poor socio-economic status of schools decreases effort.

These results take into account the multiple facets of the mechanisms by which ethnic identity triggers children's motivation to exert effort; they encompass the influence of parents and school peers belonging to the same ethnic community on their adaptation, the specificity of ethnic cultures as to the importance of school, the degree of children's internal attitudes and their perceived discrimination and finally the academic standard. The interaction among all these factors is useful to understand the differences within and across ethnic groups. For instance, for a low level of perceived discrimination $D_{i}$, a scant influence of parents and peers on the adaptations of youth-small size of $\beta\left(D_{i}\right)$ and of $\lambda\left(D_{i}\right)$-may be counterbalanced by a stronger locus of control in that hard work is believed to improve academic achievements. In fact, in the case of well-adapted parents who try to transmit the same orientation, this attempt may be ineffective when children disregard their influence. Children may also overlook a similar influence by their school peers belonging to the same ethnic community. Nevertheless, if they become more aware that academic and economic success is determined by their effort, this may represent a significant incentive to effort. Notably, the influence of well-integrated parents and/or ethnic community on children's adaptation may be weakened by 
higher levels of perceived discrimination $D_{i}$, which undermines their adjustment to the host country and makes the psychological cost of diverging from the academic standard less heavy. In addition, with higher perceived discrimination, the influence of the locus of control is diminished as children become more convinced that scholastic achievement is less dependent on their own effort and more on discrimination.

Importantly, parents and pupils belonging to the same ethnic community often shape children's adaptation in a different way. This means that, for instance, when perceived discrimination $D_{i}$ rises as the environment becomes more hostile to ethnic communities, on the one hand, children may be urged by parents with strong attitudes towards adaptation to ignore prejudices and to conform to school rules. On the other hand, they may be subject to the social pressure of their peers belonging to marginalized groups, who reject adaptation as they are particularly vulnerable to discrimination in host societies and are convinced that school does not improve one's socio-economic status. When children are more responsive to their parents' influence, a rise in perceived discrimination hampers children's adaptation less $\left(\beta^{\prime}\right.$ is lower in absolute value-see (8) in the Appendix). To the contrary, if they are more reactive to their peers, the same increase in discrimination undermines their adjustment to school and motivation to achieve to a greater extent $\left(\lambda^{\prime}\right.$ is higher in absolute value-see (8) in the Appendix) if one takes into account that higher discrimination reinforces their opposition to mainstream culture.

Moreover, low academic standard-e $(S)$ - may correspond to a poor socio-economic status of schools, which often are segregated and characterized by very low expectations of teachers on students' attainments. This aspect contributes to reduce scholastic effort, which further decreases in presence of a higher level of perceived discrimination.

\section{Conclusions}

How ethnic identity triggers children's scholastic effort is a complex and multifaceted phenomenon, which entails the interaction among the influence of several factors such as parents and ethnic communities, the specificity of ethnic culture and children's attachment to it, their internal attitudes and perceived discrimination and finally schools' academic standard. All these factors differently shape the motivation to exert effort in school, and neglecting one of them may limit an in-depth understanding of the mechanisms that may lead to differences within and across ethnic groups in academic progress. In particular, parents and school peers belonging to the same ethnic community may help children to adapt to the host country culture through schooling. If adaptation is coupled with a strong impact of ethnic cultures promoting education and academic success, they determine the development of an integrated identity. The latter further encourages effort with respect to the case of children with only an adapted identity. Of relevance to our analysis, the drawbacks of the social context can be counterbalanced by the locus of control which is a personal trait of children; for instance, a scarce attitude to adjusting to the dominant culture due the influence of family and/or ethnic community may be offset by the locus of control. Children's strong belief that their effort will contribute to the pursuit of scholastic goals counterbalances this influence. Nevertheless, a higher level of perceived discrimination may inhibit academic progress; in fact, on the one hand, it undermines youth's adjustment to the host country and their locus of control and, on the other, reduces the psychological 
cost of diverging from the academic standard by weakening the identification with the host country culture. This aspect can be worsened by a low academic standard, which may reflect the poor socio-economic status of segregated schools with very low expectations of teachers on students' attainments; the effect is a further reduction in scholastic effort. Thus, in order to understand how a child may find the motivation to adjust to school in host countries, it is crucial to take into account also the interplay among the components of the external environment that shape ethnic identity through different channels of social pressure, including discrimination, and individual personal resources like the locus of control.

\section{Endnote}

${ }^{1}$ The complete expression for marketable skills is $w n_{i} e_{i}$, but for simplicity, we normalize wage $w$ to one.

\section{Appendix}

From the first-order conditions one derives

$$
\begin{aligned}
& \frac{\partial e_{i}^{*}}{\partial I_{k i}}=\frac{(1-\alpha)}{\alpha+(1-\alpha) \vartheta\left(I_{O k i}, E_{k}\right)}\left\{1-\vartheta_{I_{O k i}}\left(I_{O k i}, E_{k}\right)\left[e_{i}-e(S)\right]\right\} \beta\left(D_{i}\right) I_{k i}^{\beta\left(D_{i}\right)-1} \bar{I}_{k}^{\lambda\left(D_{i}\right)}>0 \\
& \frac{\partial e_{i}^{*}}{\partial \bar{I}_{k}}=\frac{(1-\alpha)}{\alpha+(1-\alpha) \vartheta\left(I_{O k i}, E_{k}\right)}\left\{1-\vartheta_{I_{O k i}}\left(I_{O k i}, E_{k}\right)\left[e_{i}-e(S)\right]\right\} \lambda\left(D_{i}\right) I_{k i}^{\beta\left(D_{i}\right)} \bar{I}_{k}^{\lambda\left(D_{i}\right)-1>0} \stackrel{<}{<} \\
& \frac{\partial e_{i}^{*}}{\partial E_{k}}=\frac{(1-\alpha)}{\alpha+(1-\alpha) \vartheta\left(I_{O k i}, E_{k}\right)}\left\{\gamma-\vartheta_{E_{k i}}\left(I_{O k i}, E_{k}\right)\left[e_{i}-e(S)\right]\right\}>0 \\
& \frac{\partial e_{i}^{*}}{\partial L_{i}}=\frac{(1-\alpha)}{\alpha+(1-\alpha) \vartheta\left(I_{O k i}, E_{k}\right)} \phi\left(D_{i}\right)>0 \\
& \frac{\partial e_{i}^{*}}{\partial D_{i}}=\frac{(1-\alpha)}{\alpha+(1-\alpha) \vartheta\left(I_{O k i}, E_{k}\right)}\left\{\begin{array}{c}
I_{O k i}\left(\beta^{\prime}\left(D_{i}\right) \ln I_{k i}+\lambda^{\prime}\left(D_{i}\right) \ln \bar{I}_{k}\right)+\phi^{\prime}\left(D_{i}\right) L_{i} \\
-\left[e_{i}-e(S)\right] \vartheta_{I_{O k i}}\left(I_{O k i}, E_{k}\right) I_{O k i} \\
\times\left(\beta^{\prime}\left(D_{i}\right) \ln I_{k i}+\lambda^{\prime}\left(D_{i}\right) \ln \bar{I}_{k}\right)
\end{array}\right\}<0 \\
& \frac{\partial e_{i}^{*}}{\partial e(S)}=\frac{(1-\alpha)}{\alpha+(1-\alpha) \vartheta\left(I_{O k i}, E_{k}\right)} \vartheta\left(I_{O k i}, E_{k}\right)>0
\end{aligned}
$$

\section{Acknowledgements}

I am particularly grateful to Antonio Abatemarco for his very helpful comments and patience while I was carrying out my research and I would like to thank the anonymous referee and the editor for the useful remarks.

Responsible editor: Denis Fougère

\section{Competing interests}

The IZA Journal of Development and Migration is committed to the IZA Guiding Principles of Research Integrity. The author declares that she has observed these principles.

Received: 28 June 2016 Accepted: 11 April 2017

Published online: 28 April 2017

\section{References}

Adsera A, Chiswick BR. Are there gender and country of origin differences in immigrant labor market outcomes across European destinations? J Popul Econ. 2007:20:495-526.

Akerlof GA, Kranton RE. Identity and schooling: some lessons for the economics of education. J Econ Lit. 2002;40(4): 1167-201.

Battu H, Mwale M, Zenou Y. Oppositional identities and the labor market. J Popul Econ. 2007;20:643-67. Bisin A, Patacchini E, Verdier T, Zenou Y. 'Bend It Like Beckham': Identity, socialization, and assimilation. CEPR Discussion Paper no. 5662. London, May; 2006. 
Bisin A, Patacchini E, Verdier T, Zenou Y. Ethnic identity and labour market outcomes of immigrants in Europe. Econ Policy. 2011;January:57-92.

Bourhis RY, Moise LC, Perreault S, Senecal S. Towards an interactive acculturation model: a social psychological approach. Int J Psychol. 1997;32:369-86.

Brown R, Capozza D. Social identities: Motivational, emotional, cultural influences. Hove: Psychology Press. 2006.

Casey T, Dustmann C. Immigrants' identity, economic outcomes and the transmission of identity across generations. Econ J. 2010;120:F31-51.

Chiswick CU. The economic determinants of ethnic assimilation. J Popul Econ. 2009;22(4):859-80.

Constant A, Gataullina L, Zimmermann KF. Gender, ethnic identity and work. 2006. IZA DP No. 2420.

Fordham S, Ogbu JU. Black students' school success: coping with the burden of 'acting white'. Urban Rev. 1986;18(3): 176-206.

Frable DES. Gender, racial, ethnic, sexual, and class identities. Annu Rev Psychol. 1997;48:139-62.

Giuseppina Autiero. Social and Personal Identities: Their Influence on Scholastic Effort. Review of Social Economy 2015; $73(1): 19-33$.

Giuseppina Autiero, Niall O'Higgins, Jailer of freedom and enemy of growth? The role of personal and social identities in educational choices. International Review of Applied Economics. 2016;30(5):591-604.

Haußer K. Identitatspsychologie [psychology of identity]. Berlin: Springer-Verlag; 1995.

Hirschman C, Lee J. Race and ethnic inequality in educational attainment in the United States. In: Rutter M, Tienda M, editors. Ethnicity and causal mechanisms. Cambridge: Cambridge University Press; 2005. p. 107-38.

Kao G, Thompson JS. Racial and ethnic stratification in educational achievement and attainment. Annu Rev Sociol. 2003:29:417-42.

Mayer A, Puller SL. The old boy (and girl) network: social network formation on university campuses. J Public Econ. 2008;92:329-47.

Mickelson RA. The attitude-achievement paradox among black adolescents. Sociol Educ. 1990;63(1):44-61.

Nekby L, Rödin M, Özcan G. Acculturation identity and higher education: is there a trade-off between ethnic identity and education? Int Migr Rev. 2009;43(4):938-73.

Patacchini E, Zenou Y. Racial identity and education. 2006. IZA DP No. 2046.

Phinney J. Stages of ethnic identity development in minority group adolescents. J Early Adolesc. 1989;9:34-49.

Phinney J. Ethnic identity in adolescents and adults: review of research. Psychol Bull. 1990;108(3):499-514.

Phinney J, Horenczyk G, Liebkind K, Vedder P. Ethnic identity, immigration, and well-being: an interactional perspective. J Soc Issues. 2001;57(3):493-510.

Portes A, Zhou M. The new second generation: segmented assimilation and its variants. Ann Am Acad Pol Soc Sci. 1993;530:74-96.

Rotter JB. Generalized expectancies for internal versus external control of reinforcement. Psychol Monogr. 1966; 80(Whole no. 609):1-28.

Schüller S. Parental ethnic identity and educational attainment of second-generation immigrants. J Popul Econ. 2015; 28(4):965-1004.

Tajel H, Turner J. An integrative theory of intergroup conflict. In: Austin W, Worchel S, editors. The social psychology of intergroup relations. Monterey, CA: Brooks/Cole; 1979. p. 33-47.

Van Laar C. The paradox of low academic achievement but high self-esteem in African American students: an attributional account. Educ Psychol Rev. 2000;12(1):33-61.

Yasui M, Dishion T. The ethnic context of child and adolescent problem behavior: implications for child and family interventions. Clin Child Fam Psychol Rev. 2007;10(2):137-79.

Zimmermann L, Gataullina L, Constant A, Zimmermann KF. Human capital and ethnic self-identification of migrants. 2006. IZA DP No. 2300.

\section{Submit your manuscript to a SpringerOpen ${ }^{\circ}$ journal and benefit from:}

- Convenient online submission

- Rigorous peer review

- Immediate publication on acceptance

- Open access: articles freely available online

- High visibility within the field

- Retaining the copyright to your article 